\section{O paternalismo e o juramento hipocrático}

\section{Paternalism and the hippocratic oath}

Mônica Beier 1

Giovano de Castro lannotti 2
1 Programa de Doutoramento em Bioética. Faculdade de Medicina. Universidade do Porto. Alameda Prof. Hernâni Monteiro, 4200319. Porto, Portugal. E-mail: mbeier@uai.com.br

2 Núcleo de Promoção de Saúde e Paz. Universidad Nacional de Córdoba. Argentina.

\begin{abstract}
It is said and commonly accepted that the tradition of paternalism in medicine goes back to the Hippocratic oath. This paternalism is held to be one of the manifestations of an asymmetrical relation between doctor and patient. Some of Hippocrates's writings reveal the respect of the doctor for the patient and include dialogue and patient education as necessary elements for the development of this relationship and the balancing of beneficence and independence. This is rooted in the pre-Socratic idea of nature (physis) as the representation of the divinity in the regulation of all the movements of the universe. The oath is a promise to forgo any kind of injustice and to administer life in accordance with the physician's good judgment. It can be concluded that the medical care of the sick was conceived in the context of the incapacity of the sick person to attain selfknowledge and the impossibility of the patient enlightening him or herself without the assistance of the physician and that this helped to perfect the ignorant and random movements of nature (physis), sanitizing it with sufficient reason (logismos). The paternalismo f nature (physis) was moderated and this is reflected in the medical art of Hippocrates.
\end{abstract}

Key words Paternalism, Beneficence, Hippocratic oath

\section{Resumo}

É dito e comumente aceito que tradição do paternalismo médico remonta ao juramento hipocrático. Esse paternalismo é tido como uma das manifestações de uma relação assimétrica entre médico e paciente. Ao estudar alguns dos escritos Hipocráticos, obtiveram-se referências relativas ao respeito do enfermo pelo médico que incluía o diálogo e a sua educação como elementos necessários a tal relação e a equilibrar beneficência e autonomia. Tais evidências se enraízam na noção pré-socrática de natureza (phýsis) enquanto representação da divindade na regulação de todos os movimentos universais. $O$ Juramento preconiza a abstenção de toda a injustiça e a administração do regime de vida conforme o juizo do médico. È possivel concluir que a assistência médica ao enfermo foi concebida no contexto da incapacidade do autoconhecimento do doente e da impossibilidade do mesmo se esclarecer sem auxílio do médico e que este aperfeiçoava a natureza (phýsis) em seus movimentos ignorantes e azarosos, saneando-os através de uma razão suficiente (logismós). o paternalismo da natureza (phýsis) era moderado e refletiu-se na arte médica hipocrática.

Palavras-chave Paternalismo, Beneficência, Juramento hipocrático 


\section{Introdução}

Vários autores ${ }^{1-4}$ compreenderam que o juramento hipocrático consagra o princípio da beneficência impositiva, cuja definição do tratamento recai exclusivamente sobre o médico, sem o concurso do paciente. Para eles, os princípios eticos contidos no juramento hipocrático pontuam que é dever do médico prescrever e administrar o tratamento que representa o melhor benefício possível ao paciente, sem preocupar-se com a participação do mesmo. Deste modo ele não deveria questionar nem objetar o tratamento proposto pelo médico, apenas submeter-se. ${ }^{2} \mathrm{O}$ médico regeria esta relação segundo um paternalismo forte. 1 Ainda, segundo esses autores, a medicina e os médicos da atualidade foram influenciados pelo paternalismo beneficente de Hipócrates, ou seja, agem segundo seu critério de julgamento profissional, estando o paciente sempre na condição passiva. 3,4

O termo "paternalismo" 5 teve origem na década de 1880 e pode ter, entre outras acepções, a de princípio de administração paterna; o governo de acordo com o pai; ou uma intervenção intencional sobre as preferências, desejos e ações referentes a outras pessoas com o objetivo de beneficiá-las ou evitar danos. O uso da palavra "pai" caracteriza modos paternos, tais como, agir de modo beneficente e tomar decisões relacionadas ao bem estar dos filhos. Sua analogia com o procedimento médico é ampliada a uma pessoa com treinamento, conhecimento e discernimento superiores aos do paciente $\mathrm{e}$ que se encontra em posição de autoridade para determinar quais são os seus melhores interesses, como a um filho. ${ }^{5}$ A evolução histórica da medicina foi, por sua vez, determinando ao médico uma autonomia na tomada das decisões, tanto pelo domínio técnico de um conhecimento específico, quanto pela sua legitimidade social, tornando o princípio da beneficência absoluto.

As formas de paternalismo médico podem ser caracterizadas de acordo com a capacidade das pessoas fazerem suas escolhas. ${ }^{6}$ Ao paternalismo exercido sobre pessoas com restrição da capacidade, incapazes ou incompetentes, nomeia-se paternalismo fraco e, ao exercido sobre indivíduos plenamente capazes, paternalismo forte. O paternalismo forte somente seria justificável se o paciente estivesse exposto a um dano significativo que poderia ser evitado, mas sempre com a menor restrição da sua autonomia.

A ética hipocrática baseava-se na physiologia e estava de acordo com o Juramento, cujo estudo pode ser dividido em três partes.7 Inicia-se com uma invo- cação aos deuses protetores da prática médica e um compromisso moral com os mestres, o que dá ao texto um caráter sagrado e uma ordenação moral. Depois enuncia um código ético com seis parágrafos de compromisso e finaliza com uma imprecação, assinalando as consequências derivadas do seu cumprimento ou transgressão, que invoca a punição dos que juram em nome dos deuses e não cumprem o prometido. Esse modelo de invocação aos deuses e penalização aos que não cumprem, desde cedo esteve presente na cultura grega. ${ }^{8}$ Vários escritos hipocráticos se referem a deuses tradicionais, quando proclamam que "o divino" é a causa principal das coisas humanas e associam o tratamento técnico ao regime de vida. ${ }^{9}$ Os parágrafos que seguem a invocação se referem às condutas profissionais e pessoais que o médico hipocrático deveria ter em relação à sociedade e a si mesmo. $\mathrm{O}$ primeiro parágrafo traz um compromisso familiar, antiga prática grega de transmitir os conhecimentos técnicos dentro da própria familia. Caso o aprendiz não tivesse laços de sangue com a família, ele deveria incorporar-se à ela através de um compromisso, para se tornar médico, formando um forte vinculo com o mestre. 10 Esse modelo de transmissão oral, quer teórica ou prática, de pai para filho ou de mestre para aprendiz, não foi apenas circunscrita às questões de caráter médico, algumas noções de filosofia natural e retórica eram também ensinadas desse modo. 11

\section{Considerações sobre a medicina hipocrática}

Antes de Hipócrates a medicina estava baseada em elementos da medicina arcaica, o sobrenatural e o puramente empírico.12 Eram comuns os cultos ao deus Apolo e a divinização de Asclépio em vários santuários em toda a Grécia. Asclépio foi uma figura obscura que se admite ter vivido em 1200 a.c. 13 e que depois se converteu em deus da medicina. Hipócrates, segundo a maior parte dos biógrafos antigos, era a décima oitava geração de Podaliro, filho de Asclépio, cujos descendentes subdividiramse nas famílias de Cós e de Cnido.11,14

Os dados a respeito de Hipócrates são tomados da biografia escrita por Sorano no segundo século depois de Cristo. ${ }^{14}$ Sabe-se que nasceu na ilha de Cós aproximadamente em 460 ou 459 a.c. Foi um médico destacado e itinerante. Provavelmente morreu em Tessália, em 355 a.c., com avançada idade de 104 anos. ${ }^{12}$ Para o mundo ocidental é considerado o pai da medicina e personifica o ideal de médico com os valores éticos eternos da profissão médica. 15 
$\mathrm{O}$ acontecimento mais importante da história da medicina foi o nascimento da medicina como um saber técnico, como téchne iatriké ou ars medica. A elaboração desta primeira medicina científica, a qual chamamos medicina hipocrática, durou cerca de trezentos anos ${ }^{9}$ a partir do século VI a.c. Consistiu em substituir na explicação de saúde e enfermidade todo elemento mágico ou sobrenatural por uma teoria circunscrita na esfera do homem e da natureza. ${ }^{9}$ A concepção da medicina estabeleceu-se como uma espécie de sacerdócio e, neste sentido, ao médico como uma espécie de mediador entre deuses e homens. Se diante dos deuses o homem era incapaz, o paternalismo mágico-religioso poderia ser caracterizado como fraco, entretanto, se o homem se torna capaz, esse mesmo paternalismo pode ser caracterizado como forte, ainda sobre o paradigma do destino.

A ideia fundamental é a de natureza, phýsis, uma força interna invencível, que submetia o médico hipocrático aos seus desígnios conforme sua necessidade, que admitia a possibilidade de ser aperfeiçoada pelo medico, tal azar physiologico. ${ }^{9}$ A enfermidade se dava quando a phýsis individual perdia o equilíbrio interno, perturbando o equilíbrio da relação dinâmica que havia entre o indivíduo são e o resto do cosmos. 9

Para os filósofos pré-socráticos a phýsis é o princípio, a substância primogênita, fundamento e divindade, por isso é em si mesma o princípio de tudo quanto há e, para o médico hipocrático, a phýsis é o verdadeiro princípio da realidade e o verdadeiramente divino (to theion). $9 \mathrm{O}$ médico serve a natureza com sua arte, a divina phýsis era seu guia supremo e transmitia-lhe sabedoria. ${ }^{9} \mathrm{O}$ médico só é capaz de curar as enfermidades em que uma necessidade inexorável da natureza não decretou morte ou incurabilidade do enfermo. Ele deve servir a natureza, phýsis, que foi embasada na necessidade (ananke), na justiça (dike) e no inevitável (adrastea) ${ }^{9}$

A phýsis tem sua própria razão, o lógos, ${ }^{9}$ é ordenada em si mesma e de dentro de si mesma. Ela é o arché do lógos médico, o princípio e fundamento da medicina. O ponto de partida do médico é a percepção sensorial, a "sensação do corpo" (aisthesis tou somatos) que deve ser a medida (o métron) do seu saber e o verdadeiro critério de sua certeza. 9

A phýsis tem harmonia e produz harmonia, isto é, possui forças capazes de restabelecer a ordem, uma potência curativa chamada de vis medicatrix naturae. 16 Possui princípios physiologicos de virtude ou propriedade e de movimento e oposição, chamada dýnamis. ${ }^{9}$ As mudanças ou movimentos que ocorrem na natureza poderiam surgir por necessidade (ananké) ou por azar (tikhé). No primeiro caso, as mudanças são inexoráveis, no segundo caso o homem pode intervir.

Os hipocráticos definem o estado de saúde como justo (dikaios), porque a phýsis universal é uma ordem justa; puro (katharós) numa relação amistosa com os deuses e ausência de matéria pecante ou de uma mancha religiosa e moral; belo (kalós) na aparência, como manifestação da boa ordem da phýsis; e proporcional (metrios), em polaridade com a enfermidade, uma desproporção, uma demesure. ${ }^{9}$ A enfermidade é o resultado de uma mudança nesta natureza, que ocasionava uma desproporção, constituindo um desequilíbrio geral, e deste modo, o homem enfermava em sua totalidade. Assim a enfermidade é um desequilíbrio da natureza e a saúde, seu equilíbrio. A enfermidade é um processo, uma mudança que se desenvolvia no tempo e evoluía a partir de suas causas em um curso natural, poderia ou não aceitar a intervenção da ars medica, segundo a tikhé ou a ananké.

\section{O juramento hipocrático}

O Corpus Hippocraticum $(\mathrm{CH})$, está constituído por 53 livros, 17 que abarcam mais de mil páginas. É uma coleção heterogênea em estilo, doutrina e época. Está escrita em dialeto jônico e sabe-se que boa parte dela esteve na biblioteca médica da ilha de Cós. A discussão de quais tratados teriam, de fato, sido escritos por Hipócrates não está resolvida. 14

$\mathrm{O}$ mais conhecido dos escritos do $\mathrm{CH}$ é o juramento. 18,19 Este texto, tradicionalmente usado pelos médicos, traça diretrizes éticas conhecidas. Muitos eruditos o datam do final do século $\mathrm{V}$ e primeira metade do século VI a.c., chegando, alguns, a supor que ele tenha sido escrito pelos pitagóricos como uma espécie de documento ou manifesto. 18 Denominado tradicionalmente Ius Iurandum pelos estudiosos de manuscritos, é o mais curto dos escritos médicos do CH. ${ }^{10}$ Apesar de sua antiguidade, seus preceitos éticos continuam atuais, conservando o mesmo vigor de 2500 anos atrás. ${ }^{10} \mathrm{~A}$ grande formusura do juramento se deve a que a medicina é uma arte inseparável das mais altas exigências éticas e do amor ao homem (filantropia, philanthropie). ${ }^{20}$

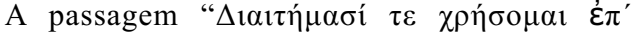

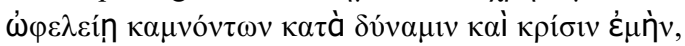

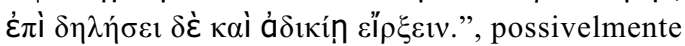
traduzida como "Aplicarei o regime de vida para o bem dos doentes, segundo meu poder e meu juízo, repelindo a maleficência e a injustiça”, tem sido 
comumente considerada uma mostra do cunho paternalista do $\mathrm{CH}$.

$\Delta ı \alpha \imath$ (dieta) tem uma complexa acepção, referindo-se tanto aos hábitos de vida, quanto ao tratamento médico em si, à moradia da pessoa, à investigação e ao governo. Xṕ̣ é ser necessário, tendo conotação de fatalidade, de destino, de imperiosidade. $\Delta v ́ v \alpha \mu \alpha 1$ é poder, conseguir, ter potência,

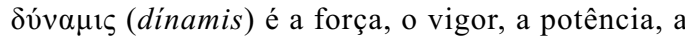
capacidade. A palavra grega крíбıৎ (crise) deve ser entendida como a ação da separação, da escolha, do julgamento, da decisão. $\Delta \eta \lambda$ ńбєı é a maleficência, o

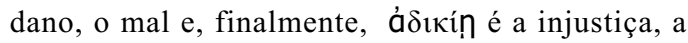
ofença.

É possível, com esses elementos, perceber que o poder discricional do médico é limitado pelo azo e pela negação da maleficência e da injustiça. Há, resta evidente, uma moderação na ação médica.

A função da diaita é ordenar a vida do paciente de tal modo que ele evite o mal, a enfermidade, e promova o bem, a saúde. ${ }^{7}$ Conseguindo um perfeito ajustamento das qualidades, a diaita promove também a justiça moral (dike). Um ajustamento da ordem natural, física e moral. É também função do médico preservar o enfermo da injustiça (adikia), que nada mais é que a atuação torpe do médico, id est, um atentado deste contra a justiça (dike) da phýsis, que é em si mesma ordenada e regular (dikaie phýsis). ${ }^{9}$ Deste modo, o médico hipocrático deve agir segundo a phýsis, sua ananke (necessidade, fatalidade) ou sua tykhé (sorte, destino, fortuidade). 18

Nesse trecho do juramento, destaca-se a pertinente ação de não causar danos, evitando o sofrimento do paciente quando sua doença é incurável. Escrito semelhante à famosa regra de honra médica atribuída a Hipócrates, primum non nocere, também exposta no livro "Epidemias I": exercitar-se a respeito das enfermidades em duas coisas, ajudar ou ao menos não causar dano, ${ }^{21}$ e acrescenta que é preciso que o enfermo oponha resistência à enfermidade junto ao médico. ${ }^{21} \mathrm{O}$ médico não deve prometer curar o impossível, ele não pode pedir à arte o que não é da arte, nem à natureza o que não é da natureza. ${ }^{9}$ É necessário que não só o médico se entregue, fazendo o devido, como também o doente e os presentes, devem se empenhar nesse mister, além do quê, as circunstâncias externas devem convergir no mesmo sentido favorável. Esta postura se assemelha à idéia de que a natureza do homem encerra uma força curativa, a vis medicatrix naturae.

Não são poucas as citações na coleção Hipocrática sobre a relação do médico com o enfermo no que diz respeito à pedagogia. Em "Sobre a Decência" o autor orienta o médico a explicar ao enfermo, de forma fácil de entender, o que vai acontecer, valendo-se da sua experiência. ${ }^{22}$ Deste modo, para o exercício da medicina, o médico tem deveres para com o enfermo, para com os demais médicos e para com a sua polis. 9

$\mathrm{O}$ autor de "Sobre a medicina antiga", ao referirse ao método da medicina e à relação com o paciente, ensina que é fundamental que o médico diga coisas inteligíveis aos profanos, afirma que estes ignorantes em medicina não podem saber como as enfermidades nascem e terminam, nem como pioram ou melhoram, mas, se os médicos as explicam serão facilmente instruídos porque irão recordar, escutando o médico, o que ele mesmos já experimentaram. 23 O médico que não se faz compreender pelos profanos e não se coloca em tal disposição, está fora da realidade. ${ }^{23}$ Esta passagem encerra várias intenções identificáveis: o médico na sociedade grega deve ensinar algo de medicina ao profano para que ele chegue a ser um homem culto; o médico deve saber qual é a verdadeira realidade do enfermo; o médico deve comunicar ao enfermo qual era a realidade de que ele padecia. Deste modo, a razão conveniente (logismós) se desenvolve na inteligência do médico a partir da exploração sensorial cuidadosa e do interrogatório detalhado.

Em "Sobre a dieta", diz-se que os profanos devem ajudar a si mesmos nas enfermidades, compreendendo o que os médicos dizem. $24 \mathrm{O}$ autor de "Sobre las afecciones", após descrever o tratamento da icterícia, afirma que se um profano souber sobre sua enfermidade, ele não recairá nela de modo irremediável da mesma forma, pois as enfermidades se tornam grandes e longas a partir de pequenos motivos, assim, o médico dever falar de modo mais natural possível ao profano. ${ }^{25}$ Ao entrar em contato com o enfermo, o médico hipocrático coloca sobre ele seu olhar e troca com ele algumas palavras. A forma de comunicação verbal (lógos), a palavra, é um dos grandes recursos metódicos do diagnóstico hipocrático ${ }^{10}$ após a exploração sensorial.

O autor de "Preceptos" aborda questões sobre o tempo e o momento oportuno, onde se faz necessária uma pronta atuação do médico, sem teorias persuasivas, com uma prática acompanhando a razão. 20 Deve-se perguntar aos profanos se eles contribuirão para o momento da cura. ${ }^{20}$ Aprende-se, por outro lado, a refletir sobre os indícios bons e maus que possam advir e, a partir deles, a formular as previsões. Somente deste modo ele poderia dizer a verdade ao enfermo, diz o autor de "O prognóstico".26

O autor de "Sobre os humores" enuncia que é 
totalmente semelhante o que beneficia e o que prejudica. 27 Orienta a indagar o enfermo sobre o tipo de sonhos e o seu sono; assinala que o médico deve ter bom ouvido e desejo de informar-se. $27 \mathrm{O}$ médico deve interrogar o enfermo sobre seu regime de vida, 25 escutar o que este diz por si mesmo, e como diz e o seu modo de sentir a enfermidade. $28 \mathrm{~A}$ respeito do tratamento, o médico deve interrogar corretamente e responder com acerto, segundo o autor de "Enfermidades I". 28 O que o enfermo diz é muito importante 28 e, como o enfermo explica e como o médico se faz entender, inclusive o uso de palavras que se relacionam com o enfermo, com os que o acompanham e os de fora, ensina o autor de "Epidemias VI".29

A ética médica hipocrática também assevera que o bom médico é honesto e regular em sua vida, suave e humanitário em seu trato, sem chegar a ser jocoso e sem deixar de ser justo, evitará a excessiva austeridade e se sentirá sempre dono de si.30 A justiça presidia todas as suas ações, ${ }^{9}$ sendo necessário que o médico hipocrático tenha o seu regime de vida. $\mathrm{O}$ médico favorece o enfermo quando, para tratá-lo, escolhe o melhor recurso ao seu alcance e dele faz uso de maneira correta e bela; 30 quando, em suas explorações, e em suas curas, sabe respeitar a honra moral do paciente. 30 Para operar esta arte o médico hipocrático atua em estreita relação com o paciente.

A "dieta" ocupa o primeiro lugar de todas as terapias descritas no $\mathrm{CH}$. Usar o "regime de vida" para o benefício dos que sofrem e repulsar o mal e a injustiça, confirma seu antropocentrismo: é a partir daí que o homem se torna individualmente a medida de todas as coisas. Um compromisso do juramento com a sociedade é considerar o doente um importante elemento na relação médico-paciente, fazendo com que a arte médica compreenda três elementos: a doença, o doente e o médico; o médico é um servidor da arte, diz o autor de "Epidemias I". ${ }^{21}$ A relação do médico com o paciente é de amizade, pois diante da enfermidade, todos devem colaborar: o enfermo, seus familiares e o médico. A saúde era o maior bem da sociedade grega e devolver esse bem ao enfermo, a mais elevada das artes.

O juramento hipocrático é o texto moral mais importante do $\mathrm{CH}, 7$ um documento que durante séculos tem representado o ideal ético do médico e que continua a influenciar a deontologia médica, cujos princípios se dividem entre o estudo das relações médico-paciente no interior de uma fraternidade e um código ético médico terapêutico, podendo chamá-los de princípios atemporais. ${ }^{7} \mathrm{Tem}$ uma fundamentação primariamente religiosa, uma elevada responsabilidade ética e ampla impunidade jurídica, ou seja, um típico juramento solene, podendo ser denominado "sacerdotal". ${ }^{7}$ Os estudos na Grécia seguiam o modelo sacerdotal, ou seja, uma responsabilidade profissional de tipo religioso. $\mathrm{O}$ pacto tinha força religiosa e moral, id est, indissolúvel, o que o diferencia do compromisso jurídico que é dissolúvel.7 $\mathrm{O}$ exercício da medicina tinha caráter idelével sendo transmitido de pai para filho. Pode-se, então, dizer que há duplicidade em suas características, sendo, além de religioso, também familiar. A transmissão de uma geração para a seguinte era feita pela memória, mnéme. ${ }^{7}$ Nos casos em que o neófito não tinha relação sanguínea com o mestre, uma relação de convivência se estabelecia pela adoção do primeiro pelo segundo. Ainda que essa relação seja análoga à paternal e também à relação sacerdotal, o sacerdócio do medico hipocrático não equivalia aos das antigas culturas Egito e da Mesopotania. Como herdeiro dos pensadores pré-socráticos, abandonaram a religiosidade popular e mítica em favor de uma physiológica. 7

\section{Considerações finais}

O fundamento da realidade do médico hipocrático é a phýsis. Ela era o divino (to theion), a natureza universal e materna, que orienta a ética profissional. Com obras e palavras o médico confessa uma religiosidade fisiológica. A deontologia hipocrática se apoia em uma religiosidade determinada e explícita. $\mathrm{O}$ médico hipocrático tem uma clara e firme consciência histórica a respeito de sua condição de médico, possuía uma ideia racional da origem da medicina e sobre o significado desta na vida do homem. Rompendo com a mentalidade mítica, ele apresenta a arte de curar como puramente humana, em cuja estrutura está a necessidade e a razão.

A assistência médica ao enfermo possui essencialmente uma dimensão ética. A medicina resultante dessa dimensão é necessariamente moral e humana e, deste modo, natural e semelhante à natureza do homem; podendo-se também afirmar que é sobretemporal. O sentido da vida do médico hipocrático é a sua arte. Dito de outra forma, a arte de curar é para ele um modo de ser homem, consistindo o eu ofício em dar alguma perfeição à phýsis, mediante obras racionalmente unidas ao que ela, em si e por si mesma, era.

Com a terapia do regime de vida, o médico ajuda a phýsis do enfermo a restaurar, em si e por si mesma, a ordem que a enfermidade havia alterado. O fundamento da prática médica é ajudar, com a teknê iatrikê, a tarefa re-ordenadora da phýsis, medi- 
ante um adequado regime de vida do enfermo, prescrevendo uma dieta conveniente. O logismós é um princípio terapêutico particular da conexão entre a ars medica e a divina phýsis, uma razão conveniente que vem da inteligência e da experiência do médico. Essa relação entre enfermidade e regime de vida fez com que o médico se tornasse virtuoso.

Alguns autores definiram o paternalismo hipocrático como uma relação assimétrica baseada puramente na beneficência. Deste modo, o médico agiria unilateralmente, justificando-se pela ideia de que sabia o melhor para o paciente, considerando que este não estava preparado para saber o que era o melhor para si.

Encontramos nos escritos hipocráticos referências relativas ao respeito do enfermo pelo médico, que incluía o diálogo e a sua educação como integrantes necessários à relação médico-paciente, fato que demonstra o equilíbrio entre beneficência e autonomia. $\mathrm{O}$ médico hipocrático agia com segurança dentro da elite social e intelectual de seu mundo, possuindo firmeza e clareza da consciência técnica, capacidade de se expressar verbalmente e sabendo da importância curativa e educativa (pedagógica) da sua arte de curar.

Quando o médico hipocrático fala com técnica aos profanos, ensina, replica e adapta, compreendendo que, se a arte tem no médico um ministro, o tem também no enfermo com quem devia se harmonizar physiologicamente.

É preciso considerar que a enfermidade é concebida, no mundo hipocrático, no contexto da incapacidade de autoconhecimento do doente e da sua impossibilidade de ser esclarecido na educação por um sábio. Autorizanos a esta compreensão a passagem contida em "Sobre a medicina antiga", que considera o profano (enfermo) aquele que por si só é incapaz de conhecer as origens de sua enfermidade, não sabendo por que causa ela aumenta ou diminuiu. Considerando-se que é indispensável na terapêutica esclarecer o enfermo, pode-se pensar que o médico

\section{Referências}

1. Cascais AF. A experimentação humana e a crise da autoregulação da biomedicina. Anál Social. 2006; vol XLI (181): 1011-31.

2. Ligiera WR. Os princípios da bioética e os limites da atuação médica. Revista Ibero-Americana de Direito Público. 2005; 20: 410-27.

3. Drumond GF. Bioética e direito médico: o princípio da beneficência na responsabilidade civil do médico. Unimontes Científica. 2001; 1:89-96.

4. Muñoz DR. Bioética: a mudança da postura ética. Rev Bras Otorrinolaringol. 2004; 5: 578-9. "aperfeiçoa" a natureza em seus movimentos ignorantes (azar) exatamente por saneá-los logicamente através do logismós. Incapaz de se esclarecer por si mesmo, o enfermo não consegue buscar e alcançar sentido para sua vida, razão da necessidade de o médico dispensar o regime.

O paternalismo da phýsis é, no mundo grego antigo, moderado e esse conceito se reflete na arte medica. Assim, nas necessidades forçosas a medida técnica não é conveniente, pois as alterações da saúde refletem a lógica da natureza e a impossibilidade do seu governo impede a manifestação de um paternalismo duro ou forte. Já os movimentos de azar da phýsis podem ser governados por um paternalismo moderado.

Não poucas vezes, considera-se que o hipocratismo se assenta sobre um paternalismo forte na relação médico-paciente. Entretanto, o estudo atento de passagens diversas em alguns dos livros do $\mathrm{CH}$, levam a possibilidade de se admitir que esse paternalismo não era forte, mas moderado. Essa proposição se baseia, sobretudo, no juramento que preconiza a abstenção de toda a injustiça e a administração do regime conforme o juízo do médico. Essa compreensão se enraíza, também, na noção présocrática de natureza enquanto representação da divindade na regulação de todos os movimentos universais.

Para o médico hipocrático, a arte médica é uma atividade apaixonante. Uma ótima contribuição ao bem geral da polis. O médico, nesse contexto, é servidor da arte e servidor da natureza, por amor ao homem; sendo ele imbuído de uma espécie de vocação profissional, ou vocação médica, uma convicção de que só se consagra à arte de curar aquele que possui o verdadeiro sentido da própria vida. A phýsis emancipava o homem e o responsabilizava no aperfeiçoamento da natureza. A medicina é, para estes homens, a salvação e o caminho para perfeição da sua natureza.
5. Beauchamp TL, Childress JF. Beneficência. In: Princípios de ética biomédica. Tradução de Luciana Pudenzi. São Paulo: Loyola; 2002. p. 296-308.

6. Feinberg J. Harm to self. The moral limits of the criminal law. Vol. three. New York. Oxford; 1986.

7. Gracia D. Fundamentos de Bioética. Madrid: Editorial Triacastela; 2007. p. 45-71.

8. Homero. Ilíada. Tradução de Mendes MO. São Paulo: Ed. Martin Claret; 2005. 
9. Entralgo PL. La Medicina Hipocrática. Madrid: Alianza Universidad; 1987.

10. Ribeiro Jr WA. O juramento. In: Textos hipocráticos, o doente, o médico e a doença. Cairus HF, Ribeiro Jr. WA. Rio de Janeiro: Ed. Fiocruz; 2005. p. 152-67.

11. Jouanna J. Hippocrate. Paris: Fayard; 1992.

12. Castiglione A. Historia da Medicina. Vol I. Traduzida por Laclette R. São Paulo: Companhia Ed. Nacional;1947. p. 174-211.

13. Nascimento CNG, Ramos MO, Lichtenstein A. Símbolo da medicina. Rev Medica. 2006; 85: 66-70.

14. Rebollo RA. O legado hipocrático e sua fortuna no período greco-romano: de Cós a Galeno. Sci Stud. 2006; 4: 45-81.

15. Brito AE. La clínica y la medicina interna. Apuntes históricos y proyecciones. Prociedente del Fórum de ciência y técnica [on line]. 2006 [Acesso em 2 abr 2010]. 83 p. Disponível em: www.forumcyt.cu/UserFiles/forum/ Textos/0601899.pdf

16. Escuela de Medicina. Pontificia univerdidad catolida de Chile Apuntes sobre Historia de la medicina. Tercera clase: La Medicina Hipocratica [on line]. [Acesso em 5 mai 2010]. Disponível em: http://escuela.med.puc.cl/ Default.html

17. Gual CG. Introdução geral. In: Gual CG, editor. Tratados hipocráticos. Vol. I. Madrid: Editorial Gredos; 1983. p. 961

18. Hippocrates. El Juramento. In: Littré E. De las obras del Grande Hipocrates. Tomo IV. Traducion Santero T. Madrid: Imprenta de Pita; 1844. p. 352-64.

19. Vintró E. Deontologia. Cap. VIII. In: Vintró E. Hipócrates y la Nosologia Hipocrática. Barcelona: Ediciones Ariel; 1972. p. 269-83.
20. Hippocrates. Preceptos. In: Gual CG, editor. Tratados hipocráticos. Vol. I. Traduccion Ferez JAL. Madrid: Editorial Gredos; 1983. p. 311-5.

21. Hippocrates. Epidemias I. In: Gual CG, editor. Tratados hipocráticos. Vol. V. Traduccion Esteban A. Madrid: Editorial Gredos; 1989. p. 62.

22. Hippocrates. Sobre la decencia. In: Gual CG, editor Tratados hipocráticos. Vol. I. Traduccion Nava MDL. Madrid: Editorial Gredos; 1983. p. 207.

23. Hippocrates. Sobre la medicina antigua. In: Gual CG, editor. Tratados hipocráticos. Vol. I. Traduccion Nava MDL. Madrid: Editorial Gredos; 1983. p. 139.

24. Hippocrates. Sobre la dieta. In: Gual CG, editor. Tratados hipocráticos. Vol. III. Traduccion Gual CG. Madrid: Editorial Gredos; 1997. p. 112.

25. Hippocrates. Sobre las afecciones. In: Gual CG, editor Tratados hipocráticos. Vol. III. Traduccion Lucas de Dios JM. Madrid: Editorial Gredos; 1997. p. 140-51.

26. Hippocrates. El pronóstico. In: Gual CG, editor. Tratados hipocráticos. Vol. I. Traduccion Gual CG. Madrid: Editorial Gredos; 1983. p. 340

27. Hippocrates. Sobre los humores. In: Gual CG, editor Tratados hipocráticos. Vol. II. Traduccion Ferez JAL. Madrid: Editorial Gredos; 2008. p. 104.

28. Hippocrates. Enfermidades I. In: Gual CG, editor. Tratados hipocráticos. Vol. VI. Traduccion Sanz AA. Madrid: Editorial Gredos; 1990. p. 27.

29. Hippocrates. Epidemias VI. In: Gual CG, editor. Tratados hipocráticos. Vol. V. Traduccion Novo EG. Madrid: Editorial Gredos; 1989. p. 220.

30. Hippocrates. Sobre el médico. In: Gual CG, editor. Tratados hipocráticos. Vol. I. Traduccion Gual CG. Madrid: Editorial Gredos; 1983. p. 173-6.

Recebido em 30 de junho de 2010

Versão final apresentada em 17 de setembro de 2010

Aprovado em 22 de novembro de 2010 